\title{
Algoritmo diagnóstico para la confirmación de casos de sarampión y rubéola en México
}

\author{
Juan Francisco Román-Pedroza, ${ }^{1}$ Edith Cruz-Ramírez, ${ }^{1}$ Kathia Elia Landín-Martínez, ${ }^{1}$ \\ Mónica Salas-García, ${ }^{1}$ Eduardo López-Ortiz, ${ }^{2}$ José Ernesto Ramírez-González, ${ }^{1}$ Irma López-Martínez ${ }^{1}$ y \\ José Alberto Díaz-Quiñonez ${ }^{2 *}$ \\ 1'Instituto de Diagnóstico y Referencia Epidemiológicos "Dr. Manuel Martínez Báez"; ${ }^{2}$ Universidad Nacional Autónoma de México, Facultad de \\ Medicina, División de Estudios de Posgrado. Ciudad de México, México
}

\section{Resumen}

Debido a la implementación exitosa de las estrategias de eliminación del sarampión y la rubéola, México enunció la interrupción de la transmisión endémica del sarampión en 1996 y de la rubéola en 2008. Después de un proceso de verificación, la región de las Américas fue declarada libre de rubéola y del síndrome de rubéola congénita en 2015 y del sarampión en 2016. Para mantener el estatus de eliminación en México es esencial continuar con la vigilancia por laboratorio en el marco de la Red Mundial de Laboratorios de Sarampión y Rubéola. El Instituto de Diagnóstico y Referencia Epidemiológicos, a través de la Red Nacional de Laboratorios de Salud Pública, garantiza resultados oportunos y confiables ante la posible reintroducción de estos y otros patógenos emergentes.

\section{PALABRAS CLAVE: Diagnóstico. Sarampión. Rubéola. México.}

\section{Abstract}

Due to the successful implementation of measles and rubella elimination strategies, Mexico announced the interruption of endemic transmission of measles in 1996 and that of rubella in 2008. After a verification process, the region of the Americas was declared free of rubella and congenital rubella syndrome in 2015 and of measles in 2016. In order to maintain the elimination status in Mexico, it is essential to continue laboratory surveillance within the framework of the Global Measles and Rubella Laboratory Network. The Institute of Epidemiological Diagnosis and Reference, through the National Network of Public Health Laboratories, guarantees timely and reliable results in view of the possible reintroduction of these and other emerging pathogens.

KEY WORDS: Diagnosis. Measles. Rubella. Mexico.

Correspondencia:

*José Alberto Díaz-Quiñonez

E-mail: adiazq@unam.mx
Fecha de recepción: 30-08-2019

Fecha de aceptación: 23-09-2019

DOI: 10.24875/GMM.19005497
Gac Med Mex. 2019;155:532-536

Disponible en PubMed www.gacetamedicademexico.com 


\section{Introducción}

El sarampión es una enfermedad febril exantemática de vigilancia obligatoria en México de acuerdo con la legislación y normatividad mexicana., ${ }^{1,2}$ La enfermedad es causada por el virus del sarampión, que pertenece al género Morbilivirus de la familia Paramixoviridae. ${ }^{3}$ Los receptores de sarampión se expresan en muchos tipos celulares, lo que explica su expresión sintomática sistémica. La transmisión ocurre por propagación de microgotas o contacto directo con secreciones nasofaríngeas a través del aire cuando una persona infectada tose o estornuda. Hasta $90 \%$ de las personas susceptibles en contacto directo con las secreciones derivadas de la tos y estornudos, o con el aire o superficies de la habitación donde se aloja el paciente, pueden ser infectadas en ese periodo. ${ }^{4}$

Los síntomas iniciales son fiebre, tos, secreción nasal y conjuntivitis, enantema, exantema maculopápular que inicia en cabeza, se extiende a tronco y extremidades. Puede cursar desde síntomas leves hasta complicaciones graves como diarrea, neumonía, crisis convulsivas por fiebre, cicatrices corneales que derivan en ceguera, encefalitis y muerte. La encefalitis ocurre en uno de 100000 casos y las defunciones en uno a tres entre 1000; los menores de cinco años y los individuos inmunocomprometidos son los más afectados. De seis a ochos años después del cuadro, uno de cada 100000 casos puede desarrollar panencefalitis esclerosante subaguda como complicación, por persistencia del virus en el líquido cefalorraquídeo. ${ }^{5}$

El periodo de incubación es de 10 a 12 días; los pródromos inician después de la exposición. El exantema aparece 14 días después de la exposición inicial, rango de siete a 18 días y 21 días para efectos de vigilancia epidemiológica. Los pacientes son contagiosos cuatro días antes del inicio del exantema y cuatro días después de su aparición. Los pacientes inmunocomprometidos son contagiosos durante toda la enfermedad. ${ }^{5}$ El Sistema Nacional de Vigilancia Epidemiológica define "caso probable" de sarampión o rubéola a toda persona de cualquier edad que presente fiebre y exantema maculopapular y uno o más de los siguientes signos y síntomas: tos, coriza, conjuntivitis 0 adenomegalias (retroauriculares, occipitales o cervicales); y como "caso confirmado" de sarampión o rubéola a todo caso probable en el que se demuestre infección por virus del sarampión o rubéola mediante técnicas de laboratorio reconocidas por el Instituto de Diagnóstico y Referencia Epidemiológicos, o caso probable que no cuente con muestra o resultado de laboratorio y que esté asociado epidemiológicamente a otro caso confirmado por laboratorio. ${ }^{6}$

En México, el Programa de Vacunación Universal cuenta con la vacuna triple viral como medida de protección específica para sarampión, rubéola y parotiditis. La primera dosis se aplica a los 12 meses de edad. Aunque en general 90 a $95 \%$ de los vacunados responde adecuadamente, se aplica una segunda dosis a los seis años de edad para que quienes presentaron falla en la respuesta inmune, desarrollen niveles protectores de anticuerpos adecuadamente. ${ }^{5}$

En septiembre de 2016, la Organización Panamericana de la Salud y la Organización Mundial de la Salud declararon a la región de las Américas como la primera del mundo libre de sarampión después de 22 años de esfuerzos coordinados al interior de los Estados miembro. El sarampión se convirtió en la quinta enfermedad prevenible por vacunación eliminada, después de la erradicación de la viruela, la poliomielitis, la rubéola y el síndrome de rubéola congénita. ${ }^{7}$ Sin embargo, durante 2017 se presentó un brote de sarampión en Venezuela, extendiéndose a Brasil y Colombia en 2018, ${ }^{8}$ derivado de la migración a estos países. Argentina, Chile, Ecuador y Perú notificaron en ese mismo año casos importados relacionados con estos países. Al cierre de 2018, Brasil, Venezuela, Estados Unidos, Perú, México, Colombia, Chile, Canadá, Ecuador, Argentina, Guatemala, Antigua y Bermudas notificaron 16514 casos confirmados. $^{9}$

Al 29 de septiembre de 2019, la Secretaría de Salud había reportado en el portal oficial del gobierno federal un total de 16 casos confirmados, ${ }^{10}$ cuatro de ellos clasificados como importados, dos en investigación y el resto asociados con importación. ${ }^{11}$

\section{Diagnóstico por laboratorio}

Como laboratorio nacional de referencia ante la Organización Panamericana de la Salud/Organización Mundial de la Salud, el Instituto de Diagnóstico y Referencia Epidemiológicos "Dr. Manuel Martínez Báez" pertenece a la Red Mundial de Laboratorios para el Diagnóstico de Sarampión y Rubéola desde 1992. Ese mismo año se inició en México la Red Nacional de Laboratorios de Diagnóstico Etiológico de Enfermedad Febril Exantemática. Actualmente la Red 


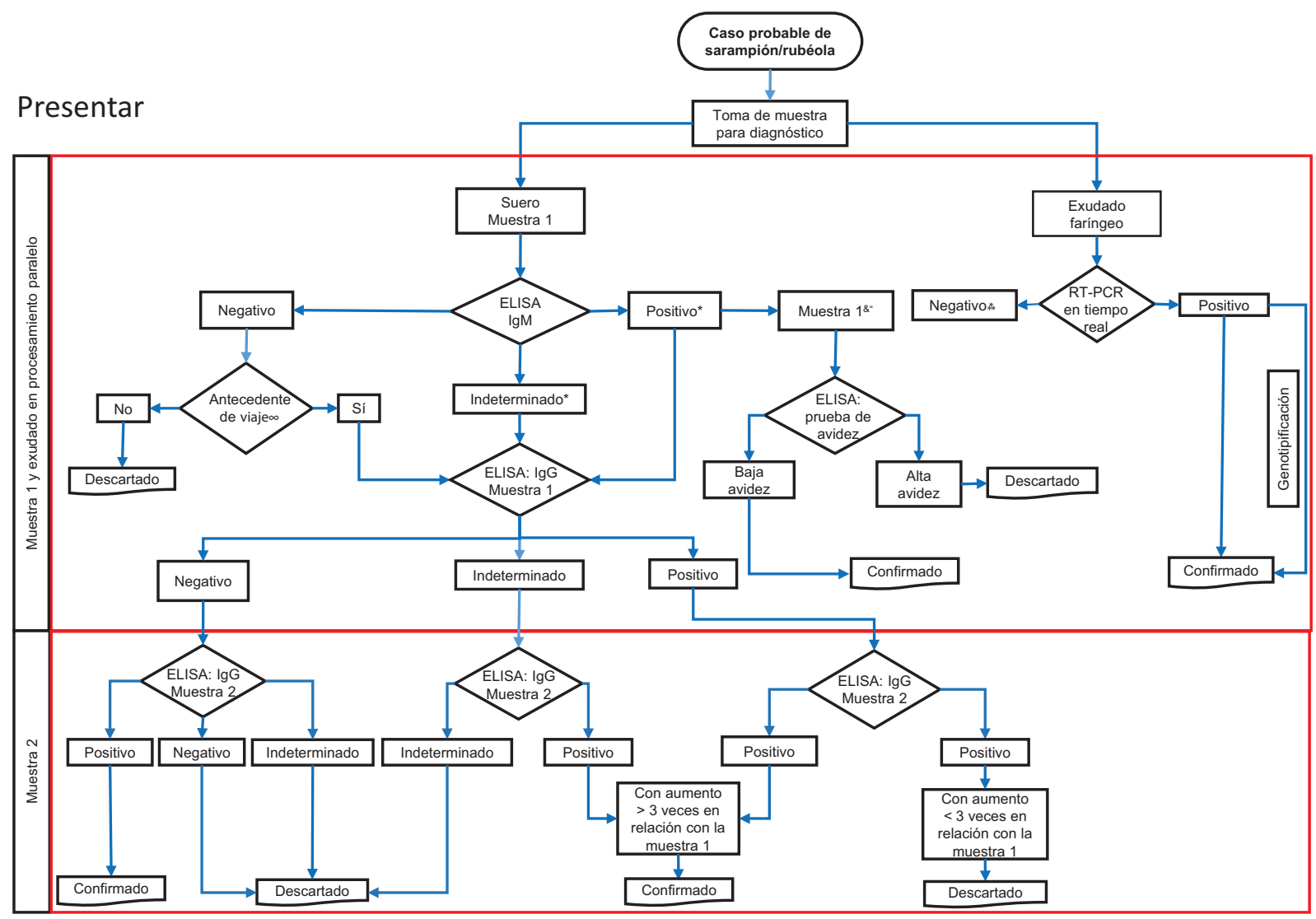

*Diagnóstico diferencial paralelo. ${ }^{\&}$ Muestra única de suero. ${ }^{\circ} \mathrm{O}$ contacto con extranjeros que provienen de países con evidencia de circulación del virus. ${ }^{*}$ Evaluar

Figura 1. Algoritmo diagnóstico por laboratorio para enfermedad febril exantemática en México. El Comité Nacional para la Vigilancia Epidemiológica valida el lineamiento de laboratorio en función del riesgo epidemiológico. Adaptado de referencia 3.

Nacional de Laboratorios de Salud Pública (RNLSP) está integrada por 31 laboratorios estatales de salud pública y el Laboratorio Central de Epidemiología del Instituto Mexicano del Seguro Social. A efecto de garantizar la calidad de la información epidemiológica y la adecuada adopción de las acciones de control, el sistema de laboratorios es evaluado mediante estándares internacionales.

El algoritmo y los procedimientos de diagnóstico emitidos por el Instituto de Diagnóstico y Referencia Epidemiológico, a través del Laboratorio de Enfermedades Febriles Exantemáticas, se establecen en los Lineamientos para la vigilancia por laboratorio de las enfermedades febriles exantemáticas, ${ }^{3}$ aprobados por el Comité Nacional para la Vigilancia Epidemiológica y de observancia obligatoria para la RNLSP (Figura 1).

\section{Toma, manejo y envío de muestra}

Las muestras para el diagnóstico de sarampión, rubéola y síndrome de rubéola congénita son suero y exudado faríngeo. Ambas se deben tomar de forma obligatoria y simultánea, con la finalidad de llevar a cabo la detección serológica y molecular, para la confirmación de casos e identificación del genotipo. Las muestras deben cumplir con la definición operacional de caso probable de sarampión/rubéola o caso probable de rubéola congénita y con los días de evolución para ser aceptadas en el laboratorio de procesamiento.

\section{Toma y manejo de muestra}

\section{Suero}

En el periodo de cero a 35 días de evolución a partir de la fecha de inicio de exantema, se debe obtener $5 \mathrm{~mL}$ de sangre por punción venosa, utilizando un tubo de plástico de extracción al vacío, sin anticoagulante, con o sin gel separador. Una vez tomada la muestra, el tubo debe rotularse con el nombre del paciente, tipo de muestra y fecha, y almacenarse entre 2 y $8{ }^{\circ} \mathrm{C}$. Es necesario separar el suero en un tubo de plástico con cierre de rosca e identificar este con datos del paciente y de la muestra. El volumen de 
suero requerido es $1 \mathrm{~mL}$. En recién nacidos, obtener $1 \mathrm{~mL}$ de sangre por punción venosa, el volumen requerido en estos casos es de 100 a $200 \mu \mathrm{L}$. En caso de requerir una segunda muestra para el seguimiento del caso, esta debe obtenerse dos semanas después de la primera, dentro de los 30 días posteriores a la aparición del exantema.

\section{Exudado faríngeo}

Debe obtenerse dentro del periodo de 0 a 5 días de evolución a partir de la fecha de inicio del exantema; se frota la pared posterior de la faringe con un hisopo estéril de dacrón o rayón, a fin de desprender las células epiteliales. El hisopo se coloca en $2 \mathrm{~mL}$ de medio de trasporte viral estéril contenido en un tubo de plástico con cierre de rosca, rotulado con el nombre del paciente, fecha de toma y tipo de muestra.

\section{Envío y transporte de la muestra}

Todo especimen biológico debe transportarse en el sistema de triple embalaje, en condiciones de refrigeración $\left(2\right.$ a $\left.8{ }^{\circ} \mathrm{C}\right)$. Las condiciones administrativas para envío y recepción de muestras se describen detalladamente en los Lineamientos para la vigilancia por laboratorio de la enfermedad febril exantemática. ${ }^{3}$ Este documento describe las condiciones en que una muestra podría ser rechazada debido a incidencias en el proceso de toma, manejo y envío.

\section{Algoritmo de diagnóstico}

En el contexto de la sostenibilidad de la eliminación de sarampión, rubéola y síndrome de rubéola congénita es fundamental la confirmación por laboratorio con un algoritmo estándar para la RNLSP.12 Las muestras de suero y exudado faríngeo se procesan paralelamente, debiendo cumplir con la definición de caso probable y los días de evolución. Todos los sueros se analizan mediante ensayo de inmunoadsorción ligado a enzima (ELISA) para sarampión/rubéola, mientras que todos los exudados faríngeos son analizados por transcripción reversa acoplada a la reacción en cadena de la polimerasa (RT-PCR), en tiempo real para ambos diagnósticos (Figura 1).

La RNLSP realiza el diagnóstico serológico para identificación de anticuerpos IgM e IgG específicos, tanto para sarampión como para rubéola, además del diagnóstico molecular por RT-PCR en tiempo real. El
Instituto de Diagnóstico y Referencia Epidemiológicos realiza la determinación de anticuerpos IgG por pruebas de avidez contra sarampión y rubéola (para diferenciar respuestas inmunes primaria y secundaria), además de métodos virológicos (aislamiento viral) y caracterización genética del virus (genotipificación), si la muestra tiene una calidad adecuada.

En países que han logrado la eliminación, como México, si una muestra tiene un resultado negativo a IgM para sarampión o rubéola y el paciente cuenta con antecedente de viaje a países con evidencia de transmisión del virus o contacto con una persona de origen extranjero que provenga de alguno de estos países, se debe solicitar una segunda muestra para evidenciar el incremento de anticuerpos IgG. En muestras con un resultado positivo a IgM para sarampión o rubéola también se requiere una segunda muestra, para evidenciar la seroconversión y el incremento en los títulos de anticuerpos IgG específicos.

\section{Estándares de calidad de la prueba}

La oportunidad y calidad en la toma y envío de muestras, hasta la recepción en el laboratorio, condicionan la confiabilidad del resultado. El lineamiento de laboratorio describe los factores que inciden en la fase preanalítica, analítica y posanalítica, en la oportunidad de la emisión del resultado para el sistema de vigilancia epidemiológica y para las partes interesadas.

\section{Recomendaciones}

Es importante que el personal de salud conozca las definiciones operacionales de caso para enfermedad febril exantemática, lo que facilitará el adecuado proceso de confirmación diagnóstica al garantizar una adecuada toma, manejo y envío de muestras. El Instituto de Diagnóstico y Referencia Epidemiológicos y la RNLSP cuentan con los recursos técnicos y profesionales para realizar un diagnóstico confiable y oportuno y respaldar las acciones de prevención y control de enfermedades.

\section{Bibliografía}

1. Ley General de Salud. México: Secretaría de Salud; 2018.

2. NOM-017-SSA2-2012, para la vigilancia epidemiológica. México: Diario Oficial de la Federación; 2013.

3. Lineamientos para la vigilancia por laboratorio de la enfermedad febril exantemática. México: Secretaría de Salud/Instituto de Diagnóstico y Referencia Epidemiológicos “Dr. Manuel Martínez Báez"; 2018.

4. Centros para el Control y la Prevención de Enfermedades [sitio web]. Transmisión del sarampión. EE. UU.: CDC; 2018. 
5. Manual de vacunación. México: Secretaría de Salud/Centro Nacional para la Salud de la Infancia y la Adolescencia; 2017.

6. Manual de procedimientos estandarizados para la vigilancia epidemioló gica de las enfermedades prevenibles por vacunación. México: Secretaría de Salud; 2018.

7. Linn L, Oliel S, Baldwin A. La región de las Américas es declarada libre de sarampión. EE. UU.: Organización Panamericana de la Salud/Organización Mundial de la Salud; 2016.

8. Organización Panamericana de la Salud. Actualización epidemiológica sarampión. Organización Panamericana de la Salud/Organización Mundial de la Salud; 2019.
9. Sistema Nacional de Vigilancia Epidemiológica. Situación epidemiológica de sarampión. México: Sistema Nacional de Vigilancia Epidemiológica/ Comité Nacional de Vigilancia Epidemiológica; 2019.

10. Dirección General de Epidemiología. Sarampión, México: Casos Confirmados al 29/09/2019. México: Secretaría de Salud; 2019. Disponible en: https://www.gob.mx/cms/uploads/attachment/file/497412/Sarampion_ Mexico_Casos_Confirmados_2019.09.29_19hrs.pdf.

11. Situación epidemiológica de sarampión. México: Secretaría de Salud: 2019.

12. Orientaciones sobre las pruebas de sarampión y de la rubéola realizadas en la red de laboratorios de la Región de las Américas. EE. UU.: Organización Panamericana de la Salud/Organización Mundial de la Salud; 2018. 